Check for updates

Cite this: RSC Adv., 2018, 8, 17927

Received 2nd March 2018 Accepted 23rd April 2018

DOI: $10.1039 / c 8 r a 01856 a$

rsc.li/rsc-advances

\section{Duckweed systems for eutrophic water purification through converting wastewater nutrients to high- starch biomass: comparative evaluation of three different genera (Spirodela polyrhiza, Lemna minor and Landoltia punctata) in monoculture or polyculture}

\begin{abstract}
Guoke Chen, ${ }^{\text {abc }}$ Yang Fang, ${ }^{\text {ac }}$ Jun Huang, (D) ac Yonggui Zhao, ${ }^{d}$ Qi Li, ${ }^{\text {abc }}$ Fan Lai, ${ }^{\text {abc }}$ Yaliang $\mathrm{Xu}^{\text {abc }}$ Xueping Tian, ${ }^{\text {abc }}$ Kaize He, ${ }^{\text {ac }}$ Yanling Jin, ${ }^{\text {ac }} \mathrm{Li} \mathrm{Tan}^{\text {ac }}$ and Hai Zhao*ac

The polyculture of different duckweed species is likely to integrate their advantages in removing pollutants and starch accumulation. Here, pilot-scale comparisons of three duckweed species (Spirodela polyrhiza K1, Lemna minor K2 and Landoltia punctata K3) in monoculture and polyculture were investigated. Results showed that the TN (total nitrogen) and TP (total phosphorus) in wastewater decreased from 6.0 and $0.56 \mathrm{mg} \mathrm{L}^{-1}$ to below 0.5 and $0.1 \mathrm{mg} \mathrm{L}^{-1}$, respectively. Namely, the water quality improved to Grade II under the Chinese standard. The highest TN and TP removal efficiencies were found to be $99.1 \%$ and $90.8 \%$ in the polyculture. Besides, the starch content of S. polyrhiza K1, L. minor K2, L. punctata K3 and the polyculture reached $24.8 \%, 32.3 \%, 39.3 \%$ and $36.3 \%$, respectively. Accordingly, their average starch accumulation rates were $1.65,2.15,3.11$ and $2.72 \mathrm{~g} \mathrm{~m}^{-2} \mathrm{~d}^{-1}$, respectively. Our results suggested that $L$. punctata K3 was a promising energy feedstock due to it having the highest starch production. The advantages of different duckweed species were investigated. In the polyculture, the pollutants were efficiently removed from wastewater, with a high starch accumulation. This study supplies a new insight into the application of duckweed in eutrophic water advanced treatment coupled with starch production.
\end{abstract}

\section{Introduction}

Two thirds of the world's population currently live in areas that experience water scarcity for at least one month a year. ${ }^{1}$ In China and India, around $50 \%$ of the people face this level of water shortage. ${ }^{1}$ On the other hand, over $80 \%$ of wastewater is discharged into the environment without adequate treatment around the world. ${ }^{1}$ Domestic wastewater often contains high levels of nitrogen and phosphate. The release of these pollutants can further lower the quality of freshwater and accelerate the eutrophication of coastal marine ecosystems. ${ }^{2,3}$ Facing the ever-growing water demand, the paradigm of wastewater management has to shift from 'treatment and disposal' to 'reuse, recycle and resource recovery'. Meanwhile, an ecologically friendly and cost-effective solution is needed.

\footnotetext{
${ }^{a}$ Key Laboratory of Environmental and Applied Microbiology, Chengdu Institute of Biology, Chinese Academy of Sciences, Chengdu 610041, China

${ }^{b}$ University of Chinese Academy of Sciences, Beijing 100049, China

${ }^{c}$ Environmental Microbiology Key Laboratory of Sichuan Province, Chengdu 610041, China. E-mail: zhaohai@cib.ac.cn; Fax: +86 28 82890733; Tel: +86 2882890725

${ }^{d}$ Institute of Environmental Sciences and Ecological Restoration, School of Ecology and Environmental Sciences, Yunnan University, Kunming 650091, China
}

Many wastewater treatment processes have been designed to improve water quality. For example, activated sludge system, as a conventional microbial treatment process, can convert ammonia into gaseous nitrogen (e.g., $\mathrm{N}_{2}, \mathrm{NO}_{x}$ ), and remove phosphorus from wastewater in the form of sludge, thereby improving water quality. ${ }^{4-6}$ However, this process cannot facilitate the recovery of pollutants from wastewater, ${ }^{5}$ and wastewater advanced treatment is of high-cost. Meanwhile, the growing volume of sludge also increases the burden to environment. Aquatic plants, such as water hyacinth, giant reed, microalgae and duckweed, have shown the capability in pollutants removal and were potential feedstock candidates for biofuel production. ${ }^{3,7-10}$ However, due to the high content of lignocellulose in water hyacinth and giant reed, their biomass cannot be easily degraded, the large-scale production is limited. ${ }^{11}$ As for microalgae, its commercial application in biofuel is also limited by the high operating costs, low productivity of algal biomass, and high energy consumption during algal cell harvest. ${ }^{12,13}$

Duckweed, a kind of floating aquatic plant, is widely distributed around the world and comprised of 37 species in 5 genera (Spirodela, Lemna, Landoltia, Wolffia and Wolffiella). ${ }^{3}$ 
Duckweed reproduces almost exclusively asexually despite being flowering plants, thereby allocating almost all their resources to vegetative growth. ${ }^{14}$ Thus, it grows faster than most other plants and can double its biomass in 2 days. ${ }^{15-17}$ Duckweed is able to grow on the surface of wastewater and remove pollutants (especially nitrogen and phosphorous) from wastewater at high rates. Due to this ability, duckweed has already been used for the treatment of domestic, industrial, and swine wastewaters. ${ }^{18-22}$ In addition, the duckweed system can effectively accumulate high content of starch. The starch content of 64.9\% (dry weight) can be achieved in duckweed during nutrients starvation. ${ }^{15,23}$ Meanwhile, compared with other plants, duckweed has a lower fiber and lignin content. ${ }^{24-26}$ These features make it feasible for duckweed to be a feedstock for bioethanol production. It has been documented that the ethanol yield could achieve 24.1-30.8 $\mathrm{g} \mathrm{L}^{-1}$ converting from duckweed biomass. $^{25,27}$ In consideration of the above two points, duckweed system has the potential to be a coupled bioreactor for wastewater treatment and energy production.

Huge differences appear for duckweed in recovering pollutants from wastewater and starch accumulation. This is associated with duckweed species, climate and geographical isolates. ${ }^{\mathbf{1 8 , 2 8 , 2 9}}$ Lemna minor has the advantages in wastewater treatment, while Landoltia punctata exhibits additional advantage in starch biomass production. ${ }^{29}$ As such, the polyculture of different duckweed species make it possible to integrate their advantages, and to develop a coupled system for wastewater treatment and energy biomass production. Besides, because the single duckweed species system is susceptible to be contaminated by other species, the time and energy will be spent on remaining a single species throughout industrial operation. From the above, it was necessary to evaluate the duckweed in polyculture of different species.

Most previous studies focused on comparative study of different duckweed species in single culture ${ }^{29}$ or effects of the combinations of duckweed species in laboratory scale. ${ }^{18}$ However, there are rarely any comparative evaluations of different duckweed species between monoculture and polyculture in pilot scale, especially about treating eutrophic lake water. Compared with laboratory research, open field environment is relatively more complex, and better represents actual condition of large-scale duckweed culture. Therefore, pilot-scale study under field condition is crucial in industrial applications of duckweed. For instance, in order to highlight the potential of duckweed biomass harvested from wastewater treatment plant for methane production, a pilot system, comprising an anaerobic pretreatment and two duckweed ponds designed in series (10 $\mathrm{m}^{2}$ each), was operated with real domestic sewage. ${ }^{19}$

Selecting appropriate duckweed from the local species rather than exogenous species will help to avoid biological invasion and maximize the growth rate. These are the keys to establishing an effective duckweed cropping system.

On the basis of the above, the objectives of this study are to evaluate the ability of three local duckweed species (Spirodela polyrhiza K1, Lemna minor $\mathrm{K} 2$ and Landoltia punctata $\mathrm{K} 3$ ) for eutrophic water advanced treatment and starch production, either in polyculture or in monocultures at the pilot-scale. In order to avoid the interspecific and intraspecific competition among duckweed, a harvest regime of 4 days was adopted (Experimental section: 2.3 Operation and sampling). While previous studies focused on the potential of duckweed in monocultures, this study will offer a new perspective for the application of duckweed.

\section{Experimental section}

\subsection{Location and pilot-scale system}

The pilot-scale duckweed systems were constructed and operated in the east $100 \mathrm{~m}$ of Dianchi Lake and located in Kunming city, China (longitude $102^{\circ} 47^{\prime} \mathrm{E}$, latitude $24^{\circ} 51^{\prime} \mathrm{N}$ ). As one of the seriously polluted lakes, Dianchi Lake is facing serious challenge in terms of water pollution controls.

The four parallel duckweed systems are described in Fig. 1: Spirodela polyrhiza K1-based system, Lemna minor K2-based system, Landoltia punctata K3-based system, and polyculture duckweed-based system. Polyculture duckweeds were obtained by combining three duckweed species (Spirodela polyrhiza K1, Lemna minor $\mathrm{K} 2$ and Landoltia punctata K3). Each pilot-scale

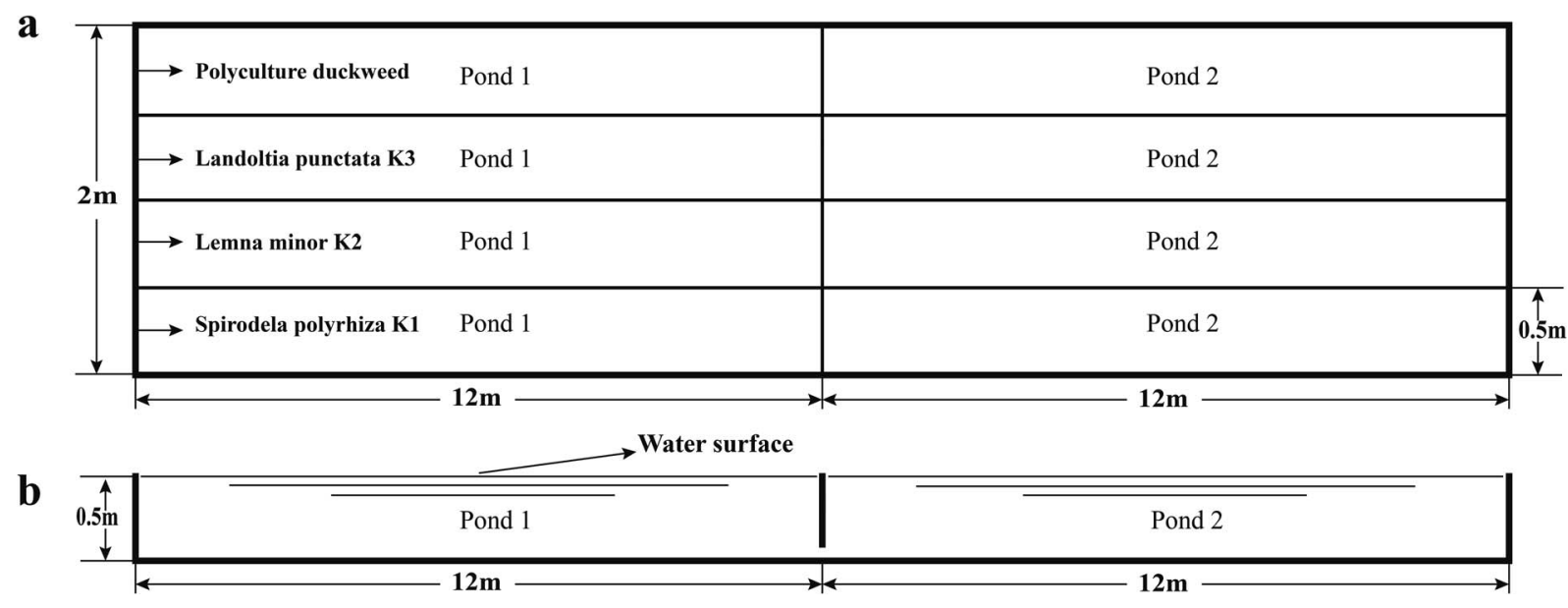

Fig. 1 The horizontal sections (a) and vertical sections (b) of the duckweed-based wastewater treatment systems. 


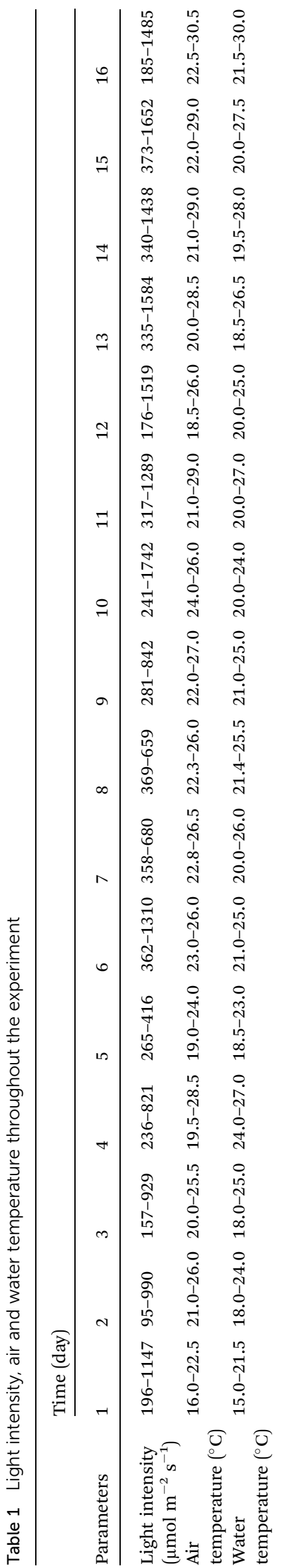

reactor was made of steel plate and featured an area of $12 \mathrm{~m}^{2}(24$ $\mathrm{m}$ length $\times 0.5 \mathrm{~m}$ width $\times 0.5 \mathrm{~m}$ water depth). To prevent the influence of wind on the duckweed, the water surface of each reactor was then divided into two equal basins (with a partition in the middle of each reactor).

\subsection{Duckweed species}

Three local duckweed species, Spirodela polyrhiza K1, Lemna minor $\mathrm{K} 2$ and Landoltia punctata $\mathrm{K} 3$ were collected and cultivated from local wastewater ponds. All of them were classified by Elias Landolt and available on an accessible webpage of Chengdu Institute of Biology and also on that of Rutgers University (Rutgers Duckweed Stock Cooperative (RDSC), http:// www.ruduckweed.org/).

\subsection{Operation and sampling}

The wastewater came from the wetland nearby Dianchi Lake. Generally, the rural domestic wastewater was discharge into the wetland and then into Dianchi Lake. Large amounts of nitrogen and phosphorus in wastewater entered into the lake, and caused eutrophication. The main characteristics of wastewater include: $\mathrm{NH}_{4}{ }^{+}-\mathrm{N}=5.98 \pm 0.09 \mathrm{mg} \mathrm{L}{ }^{-1}, \mathrm{NO}_{x}{ }^{-}-\mathrm{N}=0.03 \pm$ $0.00 \mathrm{mg} \mathrm{L}{ }^{-1}, \mathrm{TN}=6.00 \pm 0.09 \mathrm{mg} \mathrm{L}^{-1}, \mathrm{PO}_{4}-\mathrm{P}=0.41 \pm$ $0.02 \mathrm{mg} \mathrm{L}^{-1}, \mathrm{TP}=0.57 \pm 0.02 \mathrm{mg} \mathrm{L}^{-1}, \mathrm{COD}=29.88 \pm$ $6.36 \mathrm{mg} \mathrm{L}^{-1}, \mathrm{pH}=8.31 \pm 0.03$, turbidity $=12.21 \pm 0.63$. Besides, some typical heavy metals in the water body were also determined: $\mathrm{Cd}=1.5 \pm 0.1 \mu \mathrm{g} \mathrm{L}{ }^{-1}, \mathrm{Cr}=7.4 \pm 0.3 \mu \mathrm{g} \mathrm{L}{ }^{-1}$, As $=$ $11.3 \pm 1.0 \mu \mathrm{g} \mathrm{L}{ }^{-1}, \mathrm{Zn}=370.0 \pm 9.9 \mu \mathrm{g} \mathrm{L}^{-1}, \mathrm{Cu}=95.7 \pm 8.1 \mu \mathrm{g}$ $\mathrm{L}^{-1}$. Their concentrations were all very low, and reached the Chinese standard of Grade II, which is applicable to protected areas for centralized sources of drinking water. Therefore, the heavy metals in the water body were not the focus of this study. The four parallel reactors were filled with the wastewater, and then the duckweed species were introduced into two basins of each system, respectively.

Polyculture duckweed was obtained by combining the three duckweed species in a ratio of $1: 1: 1$. In order to ensure that the coverage of inoculated duckweed all were $150 \%$, the inoculated densities of duckweed were 487.5, 412.5, 375.0 and $425.0 \mathrm{~g}$ FW per $\mathrm{m}^{2}$ for $S$. polyrhiza K1, L. minor K2, L. punctata K3 and the polyculture duckweed, respectively. ${ }^{29}$ The inoculated duckweeds were all cultivated under the same condition. Their moisture content of four inoculated duckweed S. polyrhiza K1, L. minor $\mathrm{K} 2$, L. punctata $\mathrm{K} 3$ and the polyculture duckweed were 92.5\%, 92.2\%, 89.5\% and 91.4\%. Their starch contents were $5.2 \%, 4.4 \%, 9.0 \%$ and $6.2 \%$, respectively. The experiment lasted for 16 days from May 26, 2017 to June 11, 2017. The temperature and light intensity were measured four times a day at 9:00, 12:00, 15:00 and 18:00 (Table 1).

For each duckweed wastewater treatment system, the wastewater was sampled daily from three points along the treatment system (Fig. 1) for water quality analysis. To conduct a quantitative sampling and harvesting of the duckweed biomass, a harvest regime of 4 days was adopted. Three square floats (from PVC pipes, $\Phi 20 \mathrm{~mm}$ ) with an internal area of $0.1 \mathrm{~m}^{2}$ were released evenly and symmetrically on the surface of each 
basin $\left(6 \mathrm{~m}^{2}\right)$, and the fresh biomass inside the squares was collected, dehydrated and weighed $\left(W_{1}\right)$. Then, the fresh duckweed density $\left(\rho_{1}\right)$ in the basin was calculated, and the supernumerary was harvested $(\Delta S)$ by square floats (from PVC pipes, $\Phi 20 \mathrm{~mm})$. The mat density of the residual fresh duckweed after harvesting was the same as the initial inoculated duckweed densities $\left(\rho_{0}\right)$.

$$
\begin{gathered}
\rho_{1}\left(\mathrm{~g} \mathrm{~m}^{-2}\right)=\frac{W_{1}(\mathrm{~g})}{0.3\left(\mathrm{~m}^{2}\right)} \\
\Delta S\left(\mathrm{~m}^{2}\right)=\frac{\left(\rho_{1}-\rho_{0}\right) \times 6\left(\mathrm{~m}^{2}\right)}{\rho_{1}}
\end{gathered}
$$

\subsection{Analytical methods}

The fresh duckweeds were centrifuged (1000 rpm, $2 \mathrm{~min}$ ) in a dehydrator to remove the surplus water. To measure the dry weight (DW), the samples were dried at $60{ }^{\circ} \mathrm{C}$ until the weight was constant. The growth rate was measured as follows:

For each basin, growth rate $\left(\mathrm{g} \mathrm{m}^{-2} \mathrm{~d}^{-1}\right)=\Delta \mathrm{DW}(\mathrm{g}) / S\left(\mathrm{~m}^{2}\right) / t$ (day).

For each duckweed system, growth rate $\left(\mathrm{g} \mathrm{m}^{-2} \mathrm{~d}^{-1}\right)$ is the average growth rate of two basins.

$$
\text { Biomass production }\left(\mathrm{g} \mathrm{m}^{-2}\right)=\Delta \mathrm{DW}(\mathrm{g}) / S\left(\mathrm{~m}^{2}\right) \text {. }
$$

$\Delta \mathrm{DW}$ : increased biomass of dry weight (g); $S$ : water surface area in basin $\left(\mathrm{m}^{2}\right)$; $t$ : culture period $(\mathrm{d})$.

To measure the starch content, $0.03 \mathrm{~g}$ dry duckweed powder was homogenized with $600 \mu \mathrm{L} 6 \mathrm{M} \mathrm{HCl}$ in $10 \mathrm{~mL}$ centrifuge tube. Added $2 \mathrm{~mL}$ distilled water and vortex to mix thoroughly, the mixture was boiled for $2 \mathrm{~h}$ in water bath. Cooling to room temperature, adjusted $\mathrm{pH}$ to $7.0 \pm 0.5$ with $\mathrm{HCl}(6 \mathrm{M})$ or $\mathrm{NaOH}$ (6 M), added $200 \mu \mathrm{L} \mathrm{Pb}\left(\mathrm{CH}_{3} \mathrm{COO}\right)_{2}$ and diluted with distilled water to $10 \mathrm{~mL}$, completely suspended the mixture by shaking centrifuge tube, centrifuged at $5000 \mathrm{~g}$ for $5 \mathrm{~min}$. Sugars in the supernatant were analyzed by HPLC (Thermo 2795, Thermo Corp., USA) with an Evaporative Light-scattering Detector (AllTech ELSD 2000, All-tech., Corp., USA). Then the starch content was determined using the total sugar content (starch content $=$ glucose content $\times$ 0.909). ${ }^{18}$

Starch accumulation rate $\left(\mathrm{g} \mathrm{m}^{-2} \mathrm{~d}^{-1}\right)=\Delta(\mathrm{DW} \times$ starch content $)$ $(\mathrm{g}) / S\left(\mathrm{~m}^{2}\right) / t$ (day).

For water quality analysis, the wastewater was sampled daily from three points along the basin. These were then mixed to produce a composite sample for water quality analysis. Each sample was in triplicate. The $\mathrm{TN}, \mathrm{NH}_{4}{ }^{+}-\mathrm{N}, \mathrm{NO}_{3}{ }^{-}-\mathrm{N}, \mathrm{NO}_{2}{ }^{-}-\mathrm{N}$ and $\mathrm{TP}$ and $\mathrm{PO}_{4}-\mathrm{P}$ levels in wastewater were determined by the Spectroquant Analysis System PhotoLab 6100 (WTW, Germany) with the matching reagents (Merck, Germany). The digestion of sample was conducted in Thermoreactor CR 3200 (WTW, Germany). They all were measured according to the standard method. ${ }^{30}$

$$
\text { Removal efficiency }(\%)=\left(c_{0}-c\right) / c_{0} \times 100 \% \text {. }
$$

$c_{0}$ : initial pollutant concentration $\left(\mathrm{mg} \mathrm{L}^{-1}\right) ; c$ : real-time pollutant concentration $\left(\mathrm{mg} \mathrm{L}^{-1}\right)$.

\subsection{Data statistical analysis}

Each data point represents the results of three samples per experiment. SPSS (Version 15.0, SPSS Inc., US) was used for data analysis, at a 95\% confidence level to examine the significant differences.

\section{Results and discussions}

\subsection{Nitrogen and phosphorus removal}

Nitrogen and phosphorus are the main pollutants which contribute to the eutrophication of inland water, so the nitrogen concentration (TN, $\mathrm{NH}_{4}{ }^{+}-\mathrm{N}$ and $\mathrm{NO}_{x}{ }^{-}-\mathrm{N}\left(\mathrm{NO}_{3}{ }^{-}-\mathrm{N}\right.$ and $\mathrm{NO}_{2}{ }^{-}$ $\mathrm{N})$ ) and phosphorus concentration ( $\mathrm{TP}$ and $\mathrm{PO}_{4}-\mathrm{P}$ ) in wastewater were analyzed to evaluate the water quality.

The initial pollutants concentration of wastewater was 6.00 $\pm 0.09 \mathrm{mg} \mathrm{L}^{-1} \mathrm{TN}$ and $0.56 \pm 0.02 \mathrm{mg} \mathrm{L^{-1 }} \mathrm{TP}$ (worse than Grade V according to the Chinese Surface Water Environment Quality Standard (CSWEQS)). The pollutants in wastewater of different treatments were measured every two days. After 16 days' experiment, TN and TP concentration of all the four duckweed treatment systems in wastewater were below 0.5 and $0.1 \mathrm{mg} \mathrm{L}^{-1}$, respectively (Table 2). Namely, the water qualities were improved to Grade II, which is mainly applicable to protected areas for centralized sources of drinking water according to CSWEQS. In the duckweed treatment system, pollutants of wastewater could be removed by duckweed uptake, microbial conversion, sedimentation and volatilization. Among them, the contribution of duckweed uptake accounted for above $70 \% .^{31,32}$ Duckweed was reported to be used to treat relatively high concentration wastewater and exhibited good performance in nitrogen and phosphorus removals. TN and TP concentrations of wastewater decreased from 22.2 and $2.2 \mathrm{mg} \mathrm{L}^{-1}$ to 4.5 and $0.4 \mathrm{mg} \mathrm{L}^{-1}$ in 17 days, respectively. ${ }^{19}$ However, few study focused on duckweed system treating low-concentration eutrophic water in pilot scale. In this study, we first reported the water quality of eutrophic water improved to Grade II.

$\mathrm{NH}_{4}{ }^{+}-\mathrm{N}$ is the major nitrogen form in wastewater, so $\mathrm{TN}$ removal mainly relies on $\mathrm{NH}_{4}{ }^{+}-\mathrm{N}$ removal (Table 2). $\mathrm{NH}_{4}{ }^{+}-\mathrm{N}$ concentration gradually decreased from about $6.0 \mathrm{mg} \mathrm{L}^{-1}$ to below $0.1 \mathrm{mg} \mathrm{L}^{-1}$ (Table 2), reaching the Grade II according to CSWEQS. In the duckweed pond, $\mathrm{NH}_{4}{ }^{+}-\mathrm{N}$ can be removed by both duckweed uptake and bacterial transformation (nitrification/denitrification). ${ }^{31,33-35}$ Some studies suggested that aquatic plants promote both nitrification $\left(\mathrm{NH}_{4}{ }^{+}-\mathrm{N}\right.$ to $\mathrm{NO}_{3}{ }^{-}-\mathrm{N}$ and $\left.\mathrm{NO}_{2}{ }^{-}-\mathrm{N}\right)$ and denitrification $\left(\mathrm{NO}_{3}{ }^{-}-\mathrm{N}\right.$ and $\mathrm{NO}_{2}{ }^{-}-\mathrm{N}$ to $\left.\mathrm{N}_{2}\right)$ in the rhizosphere. ${ }^{36-39}$ In this study, the $\mathrm{NO}_{x}{ }^{-}-\mathrm{N}$ concentration increased in the first few days. For instance, in $S$. polyrhiza K1, 
Table 2 The nitrogen and phosphorus concentration of wastewater covered with duckweed at different days ${ }^{a}$

Nitrogen and phosphorus concentration $\left(\mathrm{mg} \mathrm{L}^{-1}\right)$

\section{Time(day)}

(A)

0

2

4

6

8

10

12

14

16

(B)

0

2

4

4
6

8

10

12

14

16

(C)

0

2

4

6

8

10

12

14

16

(D)

0

2

4

6

8

10

12

14

16
$\mathrm{NH}_{4}{ }^{+}-\mathrm{N}$

$\mathrm{NO}_{x}{ }^{-}-\mathrm{N}$

\begin{abstract}
$0.03 \pm 0.00$
$0.07 \pm 0.00$

$0.24 \pm 0.01$

$0.41 \pm 0.01$

$0.71 \pm 0.00$

$0.56 \pm 0.01$

$0.59 \pm 0.00$

$0.21 \pm 0.04$

$0.05 \pm 0.01$
\end{abstract}

$0.03+0.00$

$5.96 \pm 0.14$
$5.46 \pm 0.11$
$3.81 \pm 0.07$
$3.08 \pm 0.09$
$2.12 \pm 0.02$
$1.58 \pm 0.07$
$0.66 \pm 0.07$
$0.42 \pm 0.01$
$0.05 \pm 0.01$

$5.94 \pm 0.05$

$4.91 \pm 0.18$

$3.86 \pm 0.04$

$3.31 \pm 0.07$

$2.53 \pm 0.08$

$1.73 \pm 0.02$

$1.13 \pm 0.06$

$0.48 \pm 0.11$

$0.03 \pm 0.01$

$5.89 \pm 0.09$
$4.81 \pm 0.18$
$3.79 \pm 0.12$
$3.07 \pm 0.01$
$2.06 \pm 0.13$
$1.28 \pm 0.11$
$1.02 \pm 0.01$
$0.45 \pm 0.14$
$0.01 \pm 0.00$

$\begin{array}{ll}0.03 \pm 0.00 & 5.99 \pm 0.14 \\ 0.03 \pm 0.01 & 5.49 \pm 0.12 \\ 0.03 \pm 0.01 & 3.84 \pm 0.08 \\ 0.03 \pm 0.00 & 3.11 \pm 0.10 \\ 0.05 \pm 0.01 & 2.16 \pm 0.01 \\ 0.10 \pm 0.00 & 1.68 \pm 0.07 \\ 0.22 \pm 0.02 & 0.87 \pm 0.05 \\ 0.12 \pm 0.02 & 0.54 \pm 0.03 \\ 0.05 \pm 0.01 & 0.09 \pm 0.02\end{array}$

$0.02 \pm 0.00$

$0.04 \pm 0.01$

$0.03 \pm 0.00$

$0.04 \pm 0.01$

$0.13 \pm 0.02$

$0.18 \pm 0.00$

$0.24 \pm 0.04$

$0.38 \pm 0.06$

$0.23 \pm 0.01$

$0.03 \pm 0.00$
$0.03 \pm 0.00$
$0.06 \pm 0.00$
$0.11 \pm 0.02$
$0.21 \pm 0.01$
$0.37 \pm 0.05$
$0.08 \pm 0.00$
$0.29 \pm 0.02$
$0.05 \pm 0.00$

$6.13 \pm 0.11$
$5.42 \pm 0.04$
$3.59 \pm 0.21$
$3.24 \pm 0.03$
$2.38 \pm 0.14$
$1.40 \pm 0.11$
$0.89 \pm 0.07$
$0.24 \pm 0.04$
$0.08 \pm 0.00$
$\mathrm{PO}_{4}{ }^{-} \mathrm{P}$

$0.41 \pm 0.01$
$0.32 \pm 0.02$
$0.25 \pm 0.01$
$0.07 \pm 0.00$
$0.05 \pm 0.00$
$0.04 \pm 0.01$
$0.04 \pm 0.00$
$0.04 \pm 0.00$
$0.04 \pm 0.00$

$0.41 \pm 0.04$

$0.28 \pm 0.01$

$0.31 \pm 0.00$

$0.12 \pm 0.01$

$0.05 \pm 0.00$

$0.04 \pm 0.00$

$0.05 \pm 0.01$

$0.03 \pm 0.02$

$0.03 \pm 0.02$
$0.41 \pm 0.04$

$0.20 \pm 0.03$

$0.22 \pm 0.00$

$0.06 \pm 0.00$

$0.04 \pm 0.00$

$0.03 \pm 0.00$

$0.02 \pm 0.01$

$0.02 \pm 0.01$

$0.02 \pm 0.01$
TP

$\mathrm{NH}_{4}{ }^{+}-\mathrm{N} / \mathrm{PO}_{4}-\mathrm{P}$

removal

${ }^{a}$ (A) Represents the single culture of Spirodela polyrhiza K1; (B) represents the single culture of Lemna minor K2; (C) represents the single culture of Landoltia punctata K3; (D) represents the polyculture of Spirodela polyrhiza $\mathrm{K} 1$, Lemna minor $\mathrm{K} 2$ and Landoltia punctata $\mathrm{K}_{3}$. The $\mathrm{NH}_{4}{ }^{+}-\mathrm{N} / \mathrm{PO}_{4}-\mathrm{P}$ removal $=\left(\right.$ initial $\mathrm{NH}_{4}{ }^{+}-\mathrm{N}$ concentration - real-time $\mathrm{NH}_{4}{ }^{+}-\mathrm{N}$ concentration $) /\left(\right.$ initial $\mathrm{PO}_{4}-\mathrm{P}$ concentration - real-time $\mathrm{PO}_{4}-\mathrm{P}$ concentration $)$.

its $\mathrm{NO}_{x}{ }^{-}-\mathrm{N}$ increased from 0.03 to $0.71 \mathrm{mg} \mathrm{L}^{-1}$ in the first 8 days (Table 2), indicating that microbial nitrification prevailed over denitrification in the duckweed systems. This was probably because aerobic conditions were formed in the rhizosphere by duckweed photosynthesis, and anaerobic nitrate removal by denitrifying bacteria was hindered. ${ }^{40}$ Previous studies reported that duckweeds preferred to take up $\mathrm{NH}_{4}{ }^{+}-\mathrm{N}_{\text {over }} \mathrm{NO}_{3}{ }^{-}-\mathrm{N}$ when both nitrogen sources were available. ${ }^{41-44}$ When $\mathrm{NH}_{4}{ }^{+}-\mathrm{N}$ was consumed, the $\mathrm{NO}_{x}{ }^{-}-\mathrm{N}$ gradually decreased in the final several days of experiment (Table 2). Duckweed uptake and microbial denitrification likely contributed to the ultimate removal of nitrogen.

As evidenced by previous studies, microbial nitrification and denitrification occurred in duckweed system..$^{20,45}$ For instance, Teles et al. found that 40 genera of bacteria exhibited high abundance in duckweed system, including functional groups as nitrifying bacteria (Nitrospira and Nitrosomonas) and denitrifying bacteria (Rhodopseudomonas). ${ }^{20}$ However, unlike activated 
sludge system, microbial nitrification/denitrification was the predominant route of $\mathrm{N}$ removal. ${ }^{6}$ Duckweed uptake, which was far beyond microbial contribution, was the main way to $\mathrm{N}$ removal in duckweed system. ${ }^{20}$

In the first 10 days, the TN concentration in the $S$. polyrhiza K1-based system decreased below $1.5 \mathrm{mg} \mathrm{L}^{-1}$ (corresponded to the standard of Grade IV which is mainly applicable to the water areas for industrial use according to CSWEQS), while TN concentrations of $L$. minor $\mathrm{K} 2$, L. punctata $\mathrm{K} 3$ and the polyculture duckweed were all over $1.5 \mathrm{mg} \mathrm{L}^{-1}$ (Table 2). Then TN concentration gradually declined to below $1.0 \mathrm{mg} \mathrm{L}^{-1}$ at the end of the experiment, with the highest TN removal efficiency of $98.8 \%$ for $S$. polyrhiza K1, 98.5\% for $L$. minor $\mathrm{K} 2$ and $95.6 \%$ for $L$. punctata $\mathrm{K} 3$ and $99.1 \%$ for the polyculture, respectively (Fig. 2). The results indicated for both monocultures and polyculture, duckweed treatment systems in this study achieved high nitrogen removal. Most nitrogen presented as ammonium in this study. Ammonia nitrogen is easily absorbed by duckweed, ${ }^{\mathbf{4 6}}$ thereby led to high nitrogen removal efficiency.

Phosphorus is another major pollutant in wastewater. $\mathrm{PO}_{4}-\mathrm{P}$ accounted for approximately $70 \%$ of TP (Table 2). In this study, duckweed treatment systems showed a highly efficient removal of phosphorus. TP concentration reduced to below $0.3 \mathrm{mg} \mathrm{L}^{-1}$ (Grade IV) on day 6 for $S$. polyrhiza K1 and L. minor K2, on day 4 for $L$. punctata K3 and the polyculture (Table 2). Compared with nitrogen, TP concentration reached Grade IV earlier. After four

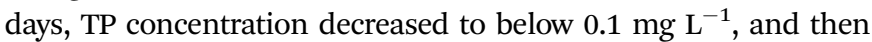

changed little till the end of the experiment. TP removal efficiency of $S$. polyrhiza K1, L. minor K2, L. punctata $\mathrm{K} 3$ and the polyculture reached $86.2 \%, 90.2 \%, 89.2 \%$ and 90.8\%, respectively (Fig. 2). Duckweed had phosphorus hyper-accumulation ability; and plant uptake was the main way for phosphorus removal. ${ }^{47}$ So phosphorus removal was easily influenced by duckweed growth. Early study reported that orthophosphate could be efficiently removed if duckweed was frequently harvested. The initial phosphate concentration decreased from $15 \mathrm{mg} \mathrm{L}^{-1}$ to $0.5 \mathrm{mg} \mathrm{L}^{-1}$ in 8 days. ${ }^{48}$

Previous studies have confirmed that the efficient bioremediation of phosphorus required a comparable level of nitrogen, with an ideal ratio of $\mathrm{NH}_{4}{ }^{+}-\mathrm{N} / \mathrm{PO}_{4}-\mathrm{P}$ uptake was about 7.0. ${ }^{34,49}$ Because $\mathrm{PO}_{4}-\mathrm{P}$ concentration gradually decreased to a low level in first 8 days and changed little for the remainder in this study, the ratio of $\mathrm{NH}_{4}{ }^{+}-\mathrm{N} / \mathrm{PO}_{4}-\mathrm{P}$ was discussed for the first 8 days. The ratio of $S$. polyrhiza $\mathrm{K} 1$, L. minor $\mathrm{K} 2$, L. punctata $\mathrm{K} 3$ and the polyculture was 12.1, 10.5, 9.2 and 11.6, respectively. Duckweed uptake was the main way for $\mathrm{PO}_{4}-\mathrm{P}$ removal, ${ }^{34}$ while $\mathrm{NH}_{4}{ }^{+}-\mathrm{N}$ could also be removed through microbial nitrification in this study. Therefore, it was reasonable that a higher ratio of $\mathrm{NH}_{4}{ }^{+}-$ $\mathrm{N} / \mathrm{PO}_{4}-\mathrm{P}$ removal was observed.

As shown in Fig. 2, the removal efficiency for TP is higher than that for TN in 12 days. This is due to low initial phosphorus concentration (the initial TN/TP was about 10.6). TN/TP removal gradually increased with duckweed system operation (Table 2), and the removal efficiency of TN finally exceeded that of TP in 1216 days (Fig. 2). The phosphate removal was lower than that of

\section{- TN removal efficiency}
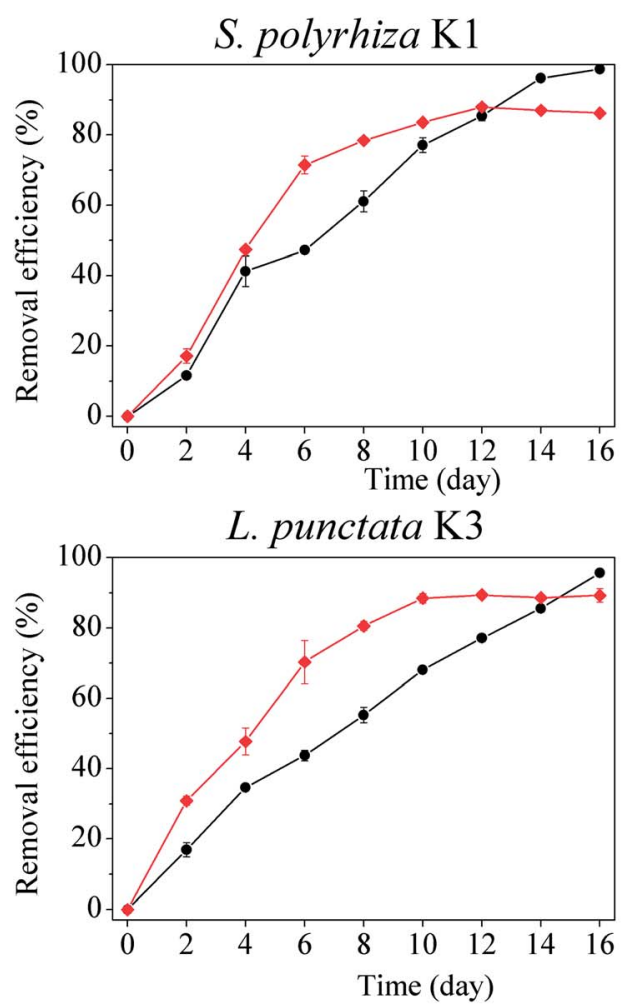

— TP removal efficiency
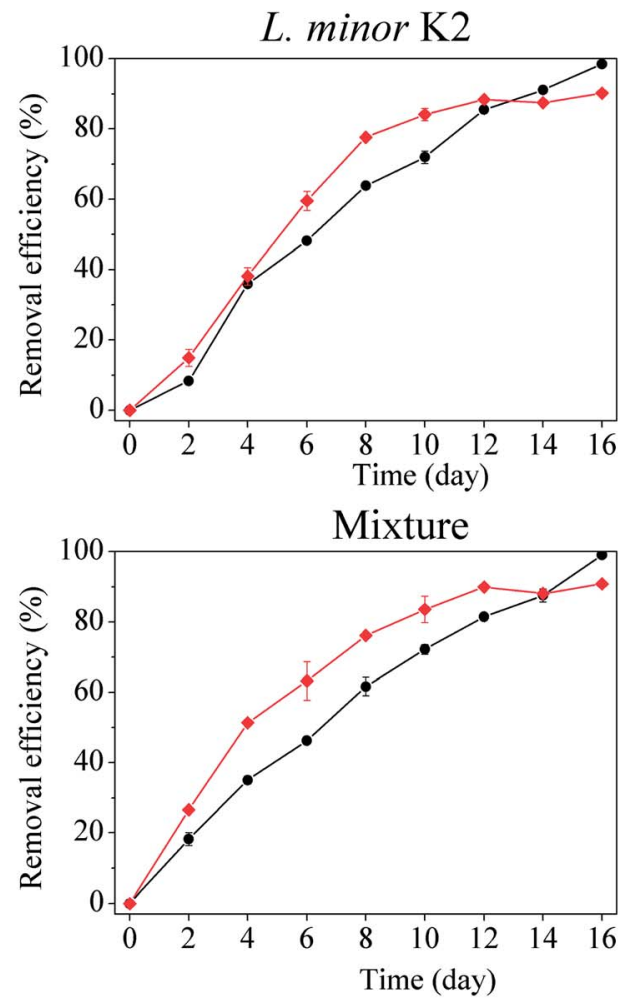

Fig. 2 TN and TP removal efficiency from wastewater in different duckweed-based treatment systems. 
a

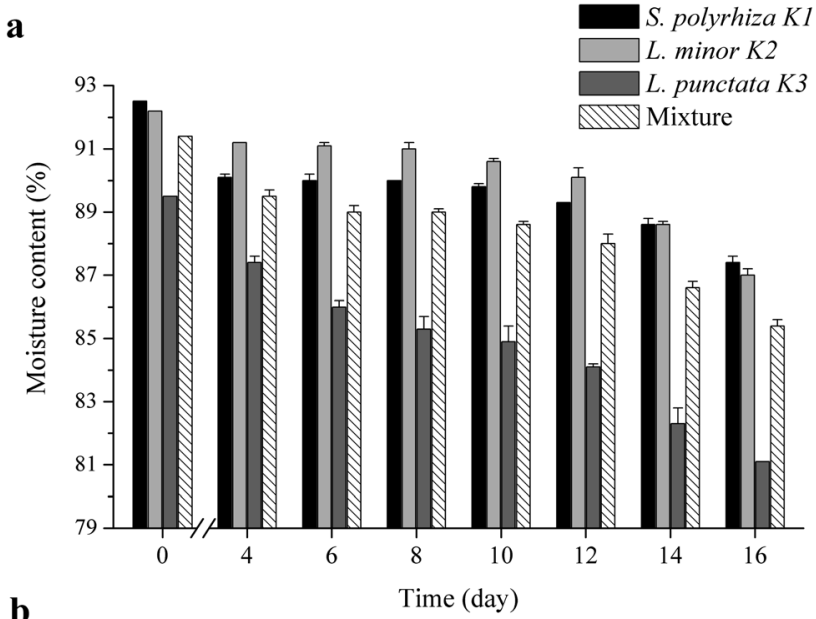

b

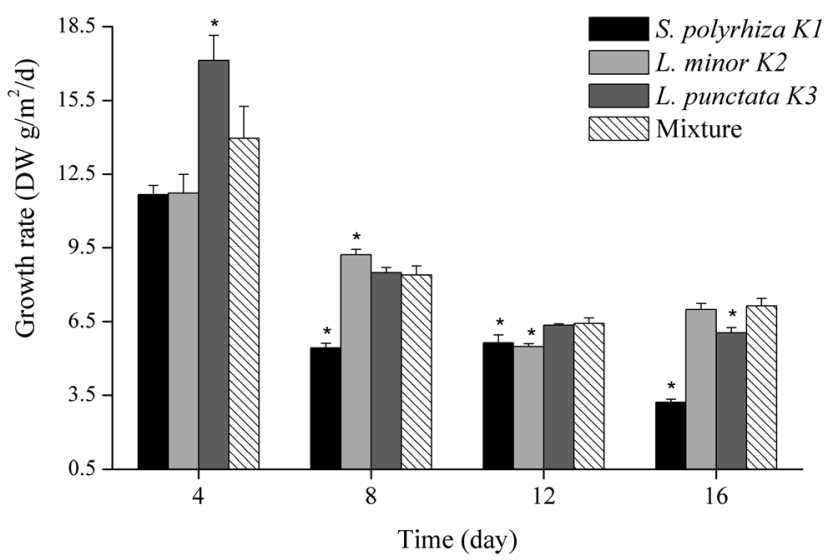

Fig. 3 The moisture content (a) and growth rate (b) of duckweed in different wastewater treatment systems. The asterisk indicated that the growth rate of S. polyrhiza K1, L. minor K2 and L. punctata K3 in single culture were significantly different from those in the polyculture with $p$ $<0.05$ according to the unpaired Student's $t$ test.

nitrogen removal in $\mathrm{N} / \mathrm{P}$ ratio of 4.25 , but phosphate removal was much higher in N/P ratio of 13.2. ${ }^{18}$ These revealed the importance of the initial N/P ratio for nutrient removal.

Although all the duckweed systems had promising performances for wastewater treatment, the polyculture duckweed treatment system exhibited a stronger ability to remove pollutants from wastewater. TN and TP removal efficiencies of the polyculture were the highest, $99.1 \%$ and $90.8 \%$, respectively (Fig. 2). These results suggested that the duckweed species in polyculture possible promoted the pollutants removal.

\subsection{Duckweed growth and biomass production}

The duckweed growth rate and the biomass production were analyzed when three duckweed species were mono-/polycultured in wastewater. Initial inoculated in wastewater, duckweed had dark green fronds and short roots and the appearance changed significantly when the pollutants were gradually consumed, finally became pale with long thick roots. When the nutrients in wastewater decreased, long thick roots made it feasible that duckweed could get nutrients for plant growth. Becoming pale was one of hunger sign in plant, suggesting that duckweed growth was hindered by nutrient deficiency. ${ }^{50}$

A common trend was observed in the four duckweed systems: the duckweed moisture content gradually decreased during the 16 days (Fig. 3a). It was reported that duckweed tended to accumulate more starch in the fronds under nutrient starvation, the internally stored starch could provide nutrients for duckweed growth in a certain significant period. ${ }^{\mathbf{5 1 , 5 2}}$ It was reasonable that more macromolecular substances were stored in duckweed led to the decline in moisture content.

In order to analyze the change of duckweed growth, the growth rate was determined every four days. As shown in Fig. $3 \mathrm{~b}$, the growth rates of $S$. polyrhiza K1, L. minor K2, $L$. punctata $\mathrm{K} 3$ and the polyculture were 11.66, 11.72, 17.13 and 13.96 DW $\mathrm{g} \mathrm{m}^{-2} \mathrm{~d}^{-1}$ in first 4 days. When the nitrogen and phosphorus were gradually consumed, growth rate of duckweed decreased. ${ }^{18}$ At the end of the experiment, the growth rates of $S$. polyrhiza K1, L. minor K2, L. punctata $\mathrm{K} 3$ and the polyculture were 3.21, 6.99, 6.04 and $7.14 \mathrm{~g} \mathrm{~m}^{-2} \mathrm{~d}^{-1}$, respectively (Fig. 3b).

Biomass production is the key consideration as industrial feedstock. In order to obtain high biomass production, the duckweeds were harvested at intervals of 4 days from each duckweed system. Their biomass production from day 4, 8, 12 and 16 were showed in Table 3. Their biomass production decreased in 16 days. Especially for $S$. polyrhiza K1, its biomass production significantly decreased from $46.66 \mathrm{~g} \mathrm{~m}^{-2}$ at day 4 to the lowest of $12.83 \mathrm{~g} \mathrm{~m}^{-2}$ at day 16 . Comparatively, the polyculture duckweed system had the highest biomass production at day 16. The average biomass production of $S$. polyrhiza K1, $L$. minor K2, L. punctata K3 and the polyculture was 25.95, 33.42, 38.02 and $35.94 \mathrm{DW} \mathrm{g} \mathrm{m}^{-2}$ (Table 3). According to the results of average biomass production, an annual yield of the duckweed could reach $23.7,30.5,34.7$ and $32.8 \mathrm{DW} \mathrm{t} \mathrm{ha}{ }^{-1}$. The biomass production of wheat grain was estimated to be $2.80 \mathrm{t} \mathrm{ha}^{-1}$ per year. ${ }^{53}$ Moreover, as a yardsticks of the practically used bioenergy crops, corn could produce $1.47-7.90 \mathrm{t} \mathrm{ha}^{-1}$ per year. ${ }^{54-56}$

Table 3 The duckweed biomass harvested from different duckweed treatment systems

\begin{tabular}{|c|c|c|c|c|}
\hline \multirow[b]{2}{*}{ Time (day) } & \multicolumn{4}{|c|}{ Biomass production ( $\mathrm{g}$ DW per $\mathrm{m}^{2}$ ) } \\
\hline & S. polyrhiza $\mathrm{K} 1$ & L. minor $\mathrm{K} 2$ & L. punctata $\mathrm{K} 3$ & Polyculture \\
\hline 4 & $46.66 \pm 1.48$ & $46.90 \pm 3.06$ & $68.50 \pm 4.05$ & $55.86 \pm 5.19$ \\
\hline 8 & $21.73 \pm 0.73$ & $36.85 \pm 0.86$ & $33.97 \pm 0.86$ & $33.61 \pm 1.47$ \\
\hline 12 & $22.57 \pm 1.28$ & $21.96 \pm 0.42$ & $25.43 \pm 0.22$ & $25.73 \pm 0.90$ \\
\hline 16 & $12.83 \pm 0.51$ & $27.96 \pm 1.02$ & $24.17 \pm 0.86$ & $28.57 \pm 1.23$ \\
\hline Average value & $25.95 \pm 7.25$ & $33.42 \pm 5.44$ & $38.02 \pm 10.39$ & $35.94 \pm 6.84$ \\
\hline
\end{tabular}


Table 4 The harvestable duckweed biomass contributed by the individual duckweed genera in the polyculture system

\begin{tabular}{llll}
\hline & \multicolumn{3}{l}{ Contribution in the polyculture system $(\%)$} \\
\cline { 2 - 4 } Time (day) & Individual & Individual & Individual \\
& S. polyrhiza $\mathrm{K} 1$ & L. minor $\mathrm{K} 2$ & L. punctata $\mathrm{K} 3$ \\
\hline 4 & 29.8 & 35.9 & 34.3 \\
8 & 25.5 & 37.8 & 36.7 \\
12 & 28.3 & 35.4 & 36.4 \\
16 & 24.8 & 37.0 & 38.2 \\
Average value & 27.1 & 36.6 & 36.4
\end{tabular}

According to the statistics from Food and Agriculture Organization of the United Nations, an annual corn yield of China was $5.95 \mathrm{t} \mathrm{ha}^{-1}$ in 2016. ${ }^{57}$ Comparison with other crops, duckweed was thus a suitable candidate as bioenergy feedstock.

In the polyculture system, the harvestable duckweed biomass contributed by the individual duckweed genera was measured (Table 4). The contribution of S. polyrhiza K1 to harvestable duckweed biomass was lower than L. minor $\mathrm{K} 2$ and $L$. punctata K3. The average contributions of $L$. minor $\mathrm{K} 2$ and $L$. punctata $\mathrm{K} 3$ were comparable, about $36.4 \%$.

\subsection{Starch content and starch production}

Besides biomass production, starch content is another essential trait for duckweed application. In green plants, starch is related with the balance of carbon, which is mainly accumulated by photosynthesis and exhausted by respiration. The starch tends to accumulate when the carbon source import (such as photosynthesis) exceeds the export (such as breathing or reproduction), and vice versa. ${ }^{50,58}$
Starch content was measured every 4 days in this study. The initial starch contents of $S$. polyrhiza K1, L. minor K2, L. punctata $\mathrm{K} 3$ and the polyculture were $5.2 \%, 4.4 \%, 9.0 \%$ and $6.2 \%$, respectively. A common trend was observed in the four duckweed systems: the duckweed starch content constantly increased during the 16 days (Fig. 4), and finally reached their highest levels of $24.8 \%, 32.3 \%, 39.3 \%$ and $36.3 \%$, respectively. Namely, the starch content of $S$. polyrhiza K1, L. minor K2, $L$. punctata $\mathrm{K} 3$ and the polyculture increased by $375 \%, 641 \%, 334 \%$ and $485 \%$, respectively. As the cultivation time increased, the $\mathrm{N}$ and $\mathrm{P}$ of wastewater were gradually consumed (Table 2), resulting in nutrition starvation for duckweed. Under nutrition starvation, the expression levels of enzymes involved in starch biosynthesis were up-regulated, whereas those involved in starch degradation showed no significant difference. This resulted in more fluxes of carbon source into starch, and led to increased starch content in duckweed. ${ }^{51,59}$ Duckweed with $24.6 \%$ starch was utilized to carry out ethanol fermentation and could achieve about $30.8 \mathrm{~g} \mathrm{~L}^{-1}$ of ethanol concentration and $90.04 \%$ of fermentation efficiency. ${ }^{27}$ To our knowledge, the duckweed with higher starch content is easier to be liquefied and saccharified for producing alcohol. The starch content in this study all exceeded $24.6 \%$. Therefore, the duckweeds cultured in this study were the suitable feedstock for alcohol fermentation.

Pearson correlation analysis indicated starch content was negatively correlated with their moisture content, namely, $S$. polyrhiza K1 $(R=-0.89, p<0.01)$, L. minor $\mathrm{K} 2(R=-0.93, p<$ $0.01)$, L. punctata $\mathrm{K} 3(R=-0.98, p<0.01)$ and the polyculture $(R$ $=-0.94, p<0.01)$. The determination of the moisture content was simpler and more economical than that of starch content. Gaining knowledge about the relation between the starch content and moisture content could be an effective method to estimate the change of starch content in duckweed starch

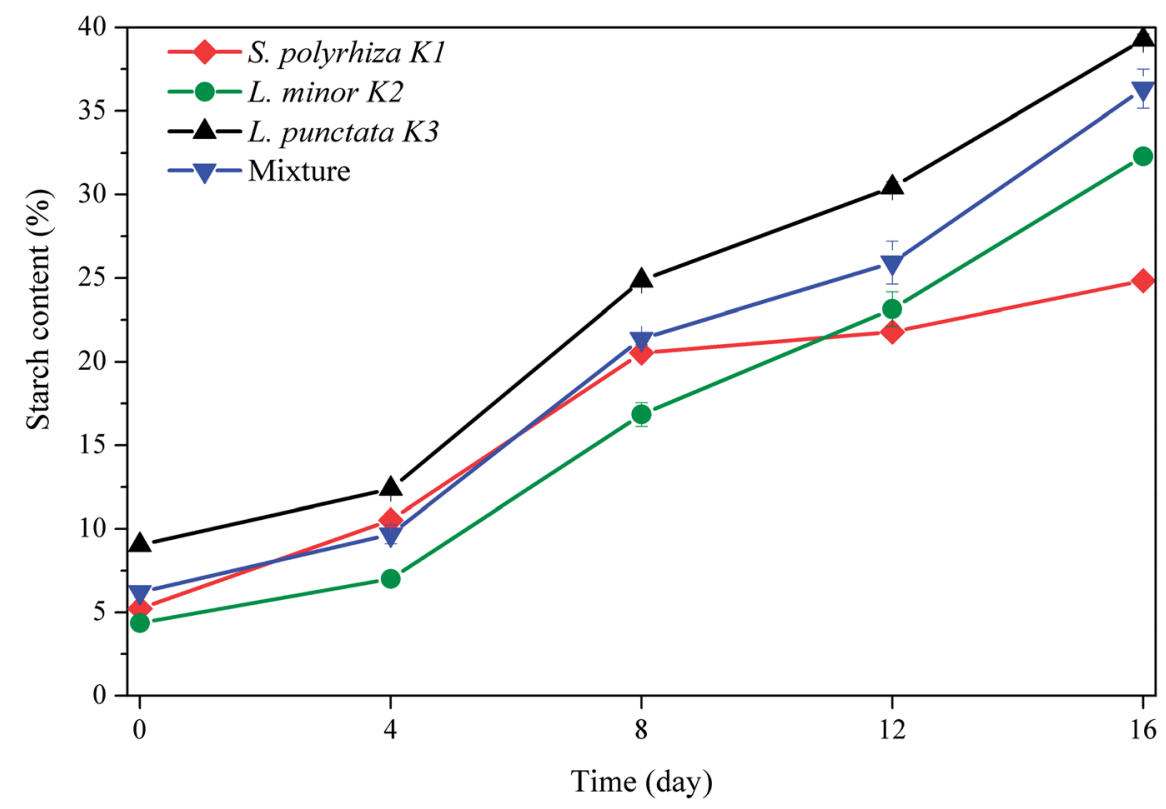

Fig. 4 Change of starch content of duckweed in different wastewater treatment systems. 
production. In addition, it was observed that the starch content in duckweed increased along with the growth rate decreasing (Fig. 3b and 4), in agreement with an early finding. ${ }^{23}$ Under insufficient nutrition, the flow of carbohydrate and energy was transformed to starch accumulation, rather than duckweed growth. ${ }^{59}$

The starch contents of the individual duckweed genera were measured in the polyculture system. As shown in Table 5, the starch content of the polyculture duckweed was generally higher than those of individual $S$. polyrhiza $\mathrm{K} 1$ and L. minor K2, and lower than that of individual L. punctata K3. These results indicated that the high starch content of the polyculture duckweed mainly attributed to the contribution from duckweed L. punctata $\mathrm{K} 3$.

Starch production of duckweed is the most important consideration for biofuel production in industrial application. The starch production of duckweed in mono-/polyculture was calculated by starch content and biomass production. Starch accumulation rate was measured every 4 days in this study. The

Table 5 The starch content of the individual duckweed genera in the polyculture system

\begin{tabular}{lcclr}
\hline \multirow{5}{*}{ Starch content $(\%)$} & & \\
\cline { 2 - 5 } & $\begin{array}{l}\text { Individual } S . \\
\text { Time }\end{array}$ & $\begin{array}{l}\text { Individual } L . \\
\text { minor } \text { K2 }\end{array}$ & $\begin{array}{l}\text { Individual } L . \\
\text { punctata } \text { K3 }\end{array}$ & Polyculture \\
\hline 4 & $9.9 \pm 0.4$ & $6.6 \pm 0.2$ & $11.6 \pm 0.4$ & $9.67 \pm 0.6$ \\
8 & $21.3 \pm 0.2$ & $17.4 \pm 0.2$ & $25.7 \pm 0.2$ & $21.37 \pm 0.4$ \\
12 & $22.3 \pm 0.2$ & $23.7 \pm 0.2$ & $31.1 \pm 0.2$ & $25.9 \pm 1.3$ \\
16 & $27.0 \pm 0.2$ & $35.1 \pm 0.3$ & $42.7 \pm 0.3$ & $36.3 \pm 1.2$
\end{tabular}

starch accumulation rate of $L$. punctata $\mathrm{K} 3$ was the highest in the first 12 days, and then was exceeded by that of the polyculture for the remainder (Fig. 5). By the end of the experiment, the starch accumulation rates of $S$. polyrhiza K1, L. minor K2, L. punctata K3 and the polyculture were 1.19, 3.19, 3.69 and 3.93 DW g m ${ }^{-2} \mathrm{~d}^{-1}$, respectively (Fig. 5). Previous reports showed that the average starch accumulation rates in 8 days were 2.90, $2.43,1.44$ and $0.95 \mathrm{DW} \mathrm{g} \mathrm{m}^{-2} \mathrm{~d}^{-1}$ respectively for L. punctata 0224 , L. japonica 0223, S. polyrhiza 0225 and W. globosa 0222. ${ }^{29}$ In general, the accumulation rate of duckweed rarely went beyond 3.0 DW $\mathrm{g} \mathrm{m}^{-2} \mathrm{~d}^{-1} \mathbf{5 , 2 9 , 5 8}$ The starch accumulation rate of the polyculture achieved nearly 4.0 DW $\mathrm{g} \mathrm{m}^{-2} \mathrm{~d}^{-1}\left(3.93 \mathrm{DW} \mathrm{g} \mathrm{m}^{-2} \mathrm{~d}^{-1}\right)$ in day 13-16.

In this study, the average starch accumulation rates of $S$. polyrhiza K1, L. minor K2, L. punctata K3 and the polyculture reached 1.65, 2.15, 3.11 and $2.72 \mathrm{DW} \mathrm{g} \mathrm{m}^{-2} \mathrm{~d}^{-1}$, respectively. It is notable that the accumulation rate of L. punctata $\mathrm{K} 3$ was the highest than that of the other three duckweed system $(p<0.01)$, and exceeded 3.0 DW g m $\mathrm{m}^{-2} \mathrm{~d}^{-1}$. This suggested L. punctata $\mathrm{K} 3$ could rapidly produce starch in this pilot-scale duckweed treatment system. The result was consistent with previous studies. Compared with other duckweed species, Landoltia punctata had significant advantage in starch accumulation. ${ }^{\mathbf{1 8 , 2 9}}$ According to the data of average starch accumulation rate in this study, the annual starch yield of L. punctata K3 could reach 11.35 DW t ha ${ }^{-1}$. It was a promising starch feedstock for alcohol fermentation. The accumulation rate of the polyculture was significantly higher than that of $S$. polyrhiza K1 $(p<0.01)$ and L. minor K2 $(p<0.01)$. This illustrated the polyculture promoted starch production compare with single culture of $S$. polyrhiza K1 and L. minor K2. The promotion observed in the polyculture system may be due to the existence of L. punctata K3, which

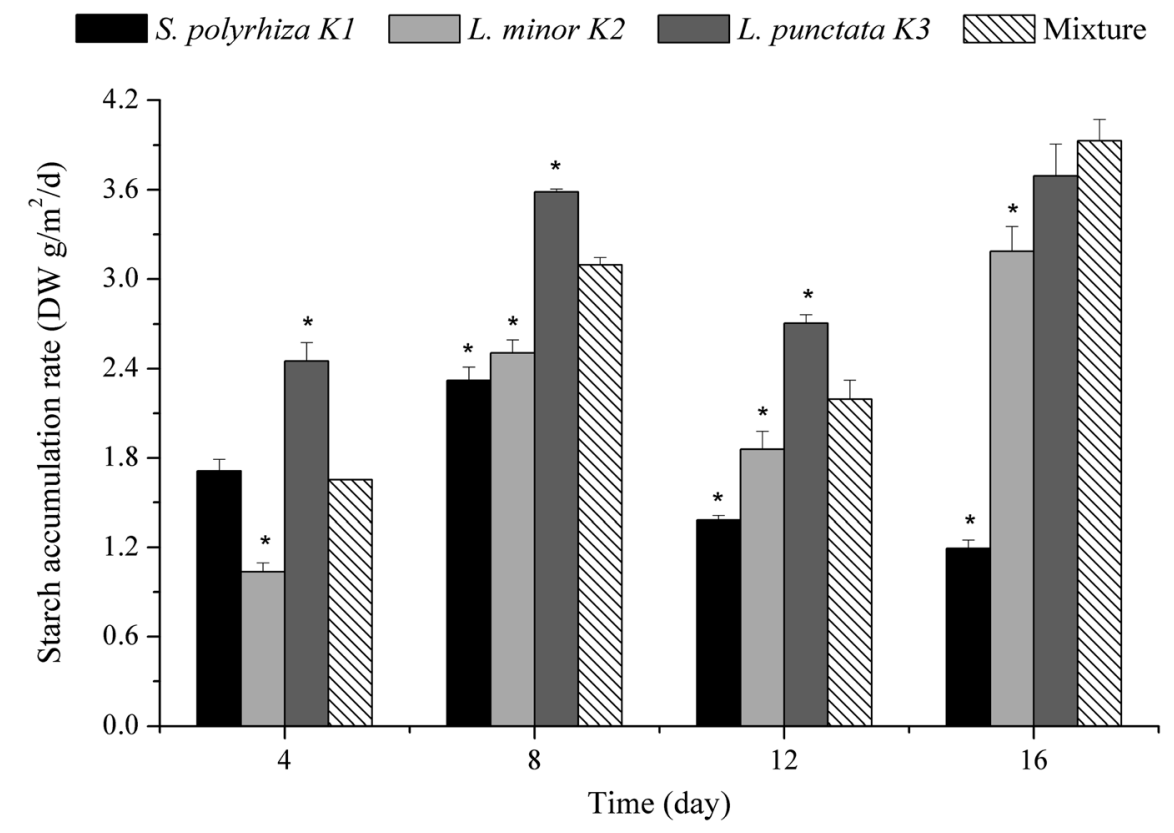

Fig. 5 The starch accumulation rate of duckweed in different wastewater treatment systems. The asterisk indicated that the starch accumulation rate of S. polyrhiza K1, L. minor K2 and L. punctata K3 in single culture were significantly different from those in the polyculture with $p<0.05$ according to the unpaired Student's $t$ test. 
showed highest starch productivity in these three duckweed species. The average accumulation rate of the polyculture reached a relatively high level of $2.72 \mathrm{DW} \mathrm{g} \mathrm{m}^{-2} \mathrm{~d}^{-1}$. It was equivalent to an annual starch yield of $9.92 \mathrm{DW} t \mathrm{ha}^{-1}$. According to the data of reports, the corn yield was 3.10-4.16 t ha $^{-1}$ per year. ${ }^{5,57,60}$ Hence, duckweed starch yield, especially in L. punctata $\mathrm{K} 3$ and the polyculture, exceeded significantly that of corn. These results strongly suggested them as the starch feedstock for alcohol production.

From the above, L. punctata K3 had the highest starch content $(39.3 \%)$ and accumulation rate $\left(3.11 \mathrm{DW} \mathrm{g} \mathrm{m}^{-2} \mathrm{~d}^{-1}\right)$. Previous study reported Lemna minor had the advantage in wastewater treatment, while Landoltia punctata exhibited additional advantage in starch production. ${ }^{29}$ In this study, the advantages of different duckweed species were integrated in polyculture. The nitrogen and phosphorus were efficiently removed from wastewater. Meanwhile, the starch was accumulated rapidly in the duckweed (2.72 DW $\mathrm{g} \mathrm{m}^{-2} \mathrm{~d}^{-1}$ ).

\section{Conclusions}

TN and TP of wastewater decreased from 6.0 and $0.56 \mathrm{mg} \mathrm{L}^{-1}$ to below 0.5 and $0.1 \mathrm{mg} \mathrm{L}^{-1}$, respectively. That is, the water quality improved from worse than Grade V to Grade II. Additionally, TN and TP removal efficiencies of the polyculture reached $99.1 \%$ and $90.8 \%$, which were higher than those of monocultures. On the other hand, L. punctata K3 had the highest starch content and accumulation rate, and was a promising starch feedstock for alcohol fermentation. The advantages of three duckweed species were integrated. The nitrogen and phosphorus were efficiently removed from wastewater in polyculture, with a high starch accumulation. This study provides a possibility for the dual applications of duckweed in eutrophic water advanced treatment and starch production.

\section{Author contributions}

Guoke Chen designed and performed the experiments, analyzed the data and wrote the manuscript; Yang Fang participated in the design of the experiments and analyzed the data; Jun Huang contributed to conceiving writing and data discussion; Yonggui Zhao participated in the design of the experiments and discussion; Qi Li, Fan Lai, Yaliang Xu and Xueping Tian participated in the data analysis and discussion; Kaize He, Yanling Jin and Li Tan participated in the part of data analysis and interpretation; Hai Zhao analyzed assay data and supervised the experiments. All authors reviewed and approved the final manuscript.

\section{Conflicts of interest}

There are no conflicts to declare.

\section{Acknowledgements}

This research was supported by the Science \& Technology Program of Sichuan Province (No. 2016SZ0070, No.
2017NZ0018, No. 2017HH0077); the Environmental Protection Program of Yunnan Province (No. 2014BI008) and the National Natural Science Foundation of China (No. 41663008).

\section{References}

1 WWAP (United Nations World Water Assessment Programme), UNESCO, 2017.

2 F. L. Zhao, W. D. Yang, Z. Zeng, H. Li, X. E. Yang, Z. L. He, B. H. Gu, M. T. Rafiq and H. Y. Peng, Biomass Bioenergy, 2012, 42, 212-218.

3 R. Verma and S. Suthar, Ecol Eng, 2014, 64, 337-343.

4 Z. Ding, I. Bourven, G. Guibaud, E. D. van Hullebusch, A. Panico, F. Pirozzi and G. Esposito, Appl. Microbiol. Biotechnol., 2015, 99, 9883-9905.

5 Y. Zhao, Y. Fang, Y. Jin, J. Huang, S. Bao, T. Fu, Z. He, F. Wang and H. Zhao, Bioresour. Technol., 2014, 163, 82-91. 6 Y. Chen, H. He, H. Liu, H. Li, G. Zeng, X. Xia and C. Yang, Bioresour. Technol., 2018, 249, 890-899.

7 L. Corno, R. Pilu and F. Adani, Biotechnol. Adv., 2014, 32, 1535-1549.

8 A. Ganguly, P. K. Chatterjee and A. Dey, Renewable Sustainable Energy Rev., 2012, 16, 966-972.

9 X. Li, W. L. Yang, H. He, S. Wu, Q. Zhou, C. Yang, G. Zeng, L. Luo and W. Lou, Bioresour. Technol., 2018, 251, 274-279.

10 L. Luo, H. He, C. Yang, S. Wen, G. Zeng, M. Wu, Z. Zhou and W. Lou, Bioresour. Technol., 2016, 216, 135-141.

11 J. Baeyens, Q. Kang, L. Appels, R. Dewil, Y. Q. Lv and T. W. Tan, Prog. Energy Combust. Sci., 2015, 47, 60-88.

12 D. Hoh, S. Watson and E. Kan, Chem. Eng. J., 2016, 287, 466473.

13 L. Christenson and R. Sims, Biotechnol. Adv., 2011, 29, 686702.

14 M. Mkandawire and E. G. Dudel, Biorem. Biodiv. Bioavail., 2007, 1, 56-71.

15 J. L. Xu, W. H. Cui, J. J. Cheng and A. M. Stomp, Biosys. Eng., 2011, 110, 67-72.

16 Y. Liu, Y. Fang, M. Huang, Y. Jin, J. Sun, X. Tao, G. Zhang, K. He, Y. Zhao and H. Zhao, Biotechnol Biofuels, 2015, 8, 64.

17 C. Yu, C. Sun, L. Yu, M. Zhu, H. Xu, J. Zhao, Y. Ma and G. Zhou, PLoS ONE, 2014, 9, e115023.

18 Z. Zhao, H. Shi, Y. Liu, H. Zhao, H. Su, M. Wang and Y. Zhao, Bioresour. Technol., 2014, 167, 383-389.

19 G. Tonon, B. S. Magnus, R. A. Mohedano, W. R. M. Leite, R. H. R. da Costa and P. Belli, Waste Biomass Valorization, 2017, 8, 2363-2369.

20 C. C. Teles, R. A. Mohedano, G. Tonon, P. B. Filho and R. H. R. Costa, Water Sci. Technol., 2017, 75, 2926-2934.

21 C. Liu, Z. Dai and H. Sun, J. Environ. Manage., 2017, 187, 497503.

22 R. Z. Gaur and S. Suthar, Process Saf. Environ. Prot., 2017, 107, 138-146.

23 Y. Xiao, Y. Fang, Y. L. Jin, G. H. Zhang and H. Zhao, Ind. Crops Prod., 2013, 48, 183-190.

24 W. Wang and J. Messing, BMC Plant Biol., 2012, 12, 5.

25 H. F. Su, Y. Zhao, J. Jiang, Q. L. Lu, Q. Li, Y. Luo, H. Zhao and M. L. Wang, Energy Fuels, 2014, 28, 3206-3216. 
26 L. Guo, Y. Ding, Y. Xu, Z. Li, Y. Jin, K. He, Y. Fang and H. Zhao, Aquat. Toxicol., 2017, 190, 87-93.

27 Q. Chen, Y. L. Jin, G. H. Zhang, Y. Fang, Y. Xiao and H. Zhao, Energies, 2012, 5, 3019-3032.

28 B. A. Bergmann, J. Cheng, J. Classen and A. M. Stomp, Bioresour. Technol., 2000, 73, 13-20.

29 Y. Zhao, Y. Fang, Y. Jin, J. Huang, S. Bao, T. Fu, Z. He, F. Wang, M. Wang and H. Zhao, Plant Biol., 2015, 17(suppl 1), 82-90.

30 APHA, AWWA and WEF, Standard methods for the examination of water and wastewater, American Public Health Association, Washington, DC, USA, 22nd edn, 2012.

31 S. A. Elshafai, F. A. Elgohary, F. A. Nasr, V. D. S. Np and H. J. Gijzen, Bioresour. Technol., 2007, 98, 798-807.

32 K. C. Bal Krishna and C. Polprasert, Ecol Eng, 2008, 34, 243250.

33 Y. Zhao, Y. Fang, Y. Jin, J. Huang, S. Bao, Z. He, F. Wang and H. Zhao, Water Sci. Technol., 2014, 70, 1195-1204.

34 J. Xu and G. Shen, Bioresour. Technol., 2011, 102, 848-853.

35 R. A. Mohedano, R. H. Costa, F. A. Tavares and P. Belli Filho, Biotechnol. Adv., 2012, 112, 98-104.

36 S. Korner, J. E. Vermaat and S. Veenstra, J. Environ. Qual., 2003, 32, 1583-1590.

37 G. Basilico, L. de Cabo, A. Magdaleno and A. Faggi, Water, Air, Soil Pollut., 2016, 227, 1-11.

38 N. Risgaard-Petersen and K. Jensen, Limnol. Oceanogr., 1997, 42, 529-537.

39 K. R. Reddy, W. H. Patrick and C. W. Lindau, Limnol. Oceanogr., 1989, 34, 1004-1013.

40 T. Toyama, T. Hanaoka, Y. Tanaka, M. Morikawa and K. Mori, Bioresour. Technol., 2018, 250, 464-473.

41 J. R. Caicedo, N. P. Van der Steen, O. Arce and H. J. Gijzen, Water Res., 2000, 34, 3829-3835.

42 M. Jayashree, B. Muthukumar and D. I. Arockiasamy, J. Environ. Biol., 1996, 17, 227-233.

43 Y. Y. Fang, O. Babourina, Z. Rengel, X. E. Yang and P. M. Pu, Ann. Bot., 2007, 99, 365-370.
44 N. Cedergreen and T. V. Madsen, New Phytol., 2002, 155, 285-292.

45 Y. Zhao, Y. Fang, Y. Jin, J. Huang, X. Ma, K. He, Z. He, F. Wang and H. Zhao, Bioresour. Technol., 2015, 179, 549558.

46 R. A. Mohedano, R. H. Costa, F. A. Tavares and P. Belli Filho, Bioresour. Technol., 2012, 112, 98-104.

47 J. B. Farrell, Master of Science, Utah State University, 2012.

48 E. Obek and H. Hasar, Fresenius Environ. Bull., 2002, 11, 2729.

49 N. Muradov, M. Taha, A. F. Miranda, K. Kadali, A. Gujar, S. Rochfort, T. Stevenson, A. S. Ball and A. Mouradov, Biotechnol. Biofuels, 2014, 7, 30.

50 L. Taiz and E. Zeiger, Plant physiology, Sinauer Associates, Sunderland, MA, 5th edn, 2010.

51 M. J. Huang, Y. Fang, Y. Xiao, J. L. Sun, Y. L. Jin, X. Tao, X. R. Ma, K. Z. He and H. Zhao, Ind. Crops Prod., 2014, 59, 299-308.

52 J. J. Cheng and A. M. Stomp, Clean: Soil, Air, Water, 2009, 37, 17-26.

53 J. M. Adams, J. A. Gallagher and I. S. Donnison, J. Appl. Phycol., 2008, 21, 569-574.

54 M. H. Duku, S. Gu and E. Ben Hagan, Renewable Sustainable Energy Rev., 2011, 15, 404-415.

55 C. Jansson, A. Westerbergh, J. M. Zhang, X. W. Hu and C. X. Sun, Appl. Energy, 2009, 86, S95-S99.

56 Z. Qin, Q. Zhuang, X. Zhu, X. Cai and X. Zhang, Environ. Sci. Technol., 2011, 45, 10765-10772.

57 FAO, FAOSTAT: Crops, http://www.fao.org/faostat/en/\#data/ QC, (accessed 15 January 2018).

58 Y. Yin, C. Yu, L. Yu, J. Zhao, C. Sun, Y. Ma and G. Zhou, Bioresour. Technol., 2015, 187, 84-90.

59 X. Tao, Y. Fang, Y. Xiao, Y. L. Jin, X. R. Ma, Y. Zhao, K. Z. He, H. Zhao and H. Y. Wang, Biotechnol. Biofuels, 2013, 6, 72.

60 A. C. Eliasson, Starch in food: structure, function and applications, CRC Press, Woodhead Pub, Boca Raton, FL, Cambridge, 2004. 